\title{
Uma abordagem metodológica do ensino sobre Energia Eólica no Ensino Médio
}

\author{
A methodological approach to teaching on wind energy in high school
F.A.R. dos Santos $^{1 *}$; L.M. Gomes ${ }^{1}$; J.G.S.L. Junior ${ }^{2}$; R. M. Gester ${ }^{1}$; L.M.Gomes Júnior $^{1}$ \\ ${ }^{\text {I}}$ Faculdade de Física/Instituto de Ciências Exatas/Licenciatura em Física, Universidade Federal do Sul e Sudeste do \\ Pará, CEP 68507-590, Marabá - Pará, Brasil \\ ${ }^{2}$ Faculdade de Física/Instituto de Ciências Exatas/Programa Nacional de Mestrado Profisional em Ensino de Física, \\ Universidade Federal do Sul e Sudeste do Pará, 68507-590, Marabá-Pará, Brasil
}

*aldenest2014@gmail.com

(Recebido em 16 de dezembro de 2016; aceito em 05 de janeiro de 2017)

\begin{abstract}
Este artigo trata do ensino aprendizagem de Física no Ensino Médio, utilizando a energia eólica como tema gerador. É feita uma discussão visando conscientizar os alunos acerca da mudança climática e o uso sustentável das fontes de energias renováveis. O tema da energia eólica no contexto das fontes renováveis de energia foi abordado em duas escolas do Ensino Médio na cidade de Marabá, estado do Pará, onde foram ministradas aulas expositivas e realizados experimentos reais e virtuais envolvendo o assunto em questão. Foram feitas avaliações buscando mensurar o nível de compreensão do tema por parte dos discentes com resultados bastante significativos.

Palavras-chave: energia eólica, experimentos reais e virtuais, ensino de Física.
\end{abstract}

This paper deals with the process of teaching and learning of Physics in high school, using wind energy as the generating theme. A discussion is held to educate students about climate change and the sustainable use of renewable energy sources. The wind energy topic in the context of renewable energy sources, was approached in two high school in Marabá City, Pará State, where lectures were given and made real and virtual experiments involving the subject in question. Evaluations were made to measure the level of understanding of the subject by students with very significant results.

Keywords: wind energy, real and virtual experiments, physics teaching.

\section{INTRODUÇÃO}

Nos dias atuais, tem havido um aumento considerável da demanda por energia e consequentemente da produção em todo o planeta - são diversos os fatores relacionados à essa busca incessante por energia, que é proveniente das mais variadas fontes, tanto renováveis quanto não renováveis. Dentre os diversos fatores citados, destacam-se os avanços tecnológicos da sociedade que demandam uma produção bastante significativa de energia que, aliados ao aumento da população mundial só tendem a agravar ainda mais o quadro da necessidade cada vez maior de energia.

Tema recorrente em discussões em todo o globo, para a maioria dos países, investir em fontes renováveis de energia que primem pela sustentabilidade significa a salvação do planeta de um apocalipse climático eminente. Nesse sentido, investir em energia renovável é mitigar pela redução da emissão de gases, como o gás carbônico $(\mathrm{CO} 2)$, e que resultem em novas opções para a geração de energia elétrica de uma forma mais limpa e eficiente. 
Nesse contexto, é imprescindível que os jovens estudantes tornem-se conscientes da importância do uso racional desses recursos energéticos, principalmente no que diz respeito à preservação do ambiente, afinal de contas, é o meio ambiente que propicia as diversas fontes de energias ao ser humano. Desse modo, é fundamental apresentar no Ensino Médio, estudos sobre as diversas fontes de energias renováveis. Assim, os alunos, através de pesquisas, apresentações e exposições, simulações e experimentos, poderão apropriar-se ainda mais de conhecimentos inerentes a conscientização dos benefícios do uso das energias renováveis.

Por outro lado, no Brasil o ensino-aprendizagem de Física é muito deficiente e passa por inúmeras dificuldades. Pode-se destacar, por exemplo, os modelos de ensino empregados por muitos professores, os currículos escolares muito extensos, carga horária muito pequena, dentre vários outros problemas. Destacam-se ainda a falta de motivação dos alunos, o fato de que professores da disciplina não utilizam uma metodologia de ensino adequada para a aprendizagem dos alunos, além, é claro, do elevado número de alunos que concluem o ensino fundamental sem praticamente nenhum domínio sobre contextualizar as ciências com o seu cotidiano. Dessa forma, para o egresso, o Ensino Médio revela-se totalmente aquém de sua realidade.

Hoje, torna-se indispensável que o ensino de Física esteja em consonância com novas tecnologias, pois diante de tanta interatividade que circula docentes, discentes, escola e a sociedade em geral, vê-se a necessidade em se utilizar desses instrumentos tecnológicos como recurso auxiliar no ensino e na aprendizagem, a exemplo, as simulações virtuais e experimentos com uso de laboratório didático de aprendizado.

Assim, este artigo apresenta uma abordagem para o ensino de Física no Ensino Médio utilizando como tema gerador a energia eólica, de modo que o docente possa a partir deste tema tão atual, trabalhar de forma mais significativa e envolvente conceitos como energia, eletromagnetismo, dinâmica dos fluidos, dentre outros. Associado a isso, utilizou-se recursos didático-metodológicos como simulações interativas no software PHET $^{\circledR}[1]$, apresentações de vídeos e uma atividade experimental.

\section{FUNDAMENTAÇÃO TEÓRICA}

\subsection{Um breve histórico}

A energia é fundamental para a manutenção da vida. Ela é tudo aquilo que é observável e compreensível no Universo pelo homem, ou mesmo o que ainda não se pode compreender ou mensurar, como é o caso da energia ou matéria escura. Aliás, os físicos costumam definir energia como sendo a capacidade de se realizar trabalho, porém tão importante quanto o conceito de energia é a existência dela em todo o Universo e nas mais variadas formas [2].

Dentre as formas de energias renováveis, destacam-se a energia eólica, a energia solar e as pequenas centrais hidrelétricas. Essas fontes apresentam a possibilidade de serem utilizadas em pequena ou grande escala, desde que exista uma política governamental que incentive sua utilização.

Do ponto de vista conceitual, a energia eólica é devida as massas de ar em movimento, ou seja, através do movimento cinético dos ventos. Ela existe em abundância em algumas regiões do planeta. O seu aproveitamento ocorre por intermédio da conversão de energia cinética de translação em energia cinética de rotação, com o emprego de turbinas eólicas, denominadas de aerogeradores.

Charles Bruch, em Clevelend, no estado de Ohio, em 1888, inventou o primeiro cata-vento destinado à geração de energia elétrica. Ele fornecia uma potência de $12 \mathrm{~kW}$ em corrente contínua, e a energia produzida era armazenada em baterias para alimentar 350 lâmpadas incandescentes [3].

No Brasil, o primeiro aerogerador em operação comercial foi instalado em 1992. Este também foi o primeiro em operação na América do Sul, instalado no arquipélago de Fernando de Noronha, e foi resultado de uma parceria entre o Centro Brasileiro de Energia Eólica e a Companhia Energética de Pernambuco [3].

A partir desse ponto, estabeleceu-se um marco nacional no desenvolvimento dos aerogeradores e consequentemente na produção em larga escala de energia elétrica advinda desse recurso natural, principalmente em regiões do país desvinculadas e não atendidas pela distribuição de energia elétrica do Sistema Integrado Nacional. 
Segundo YAMAMOTO et al. (2015) [4], o Brasil possui uma capacidade instalada de 6,79 GW e no final de 2019 serão 17,70 GW. Isso significa que a projeção da produção de energia eólica contribuirá significativamente para o aumento da matriz energética nacional. Atualmente, $o$ país, tornou-se o $4^{\circ}$ país no ranking mundial de expansão de energia eólica. Conta com 360 usinas eólicas instaladas e é o $10^{\circ}$ em capacidade mundial instalada [5].

Nos sub-tópicos seguintes serão apresentados os conceitos físicos da indução magnética e energia e potência.

\subsection{Indução Magnética}

O fenômeno da indução magnética foi descoberto na Inglaterra em 1830 por Michael Faraday. Ele descobriu que um campo magnético variando, gera um fluxo magnético variável com o tempo através de uma superfície limitada por uma espira de fio fechada e esta induz uma corrente nesse fio. Na realidade, Faraday, com a descoberta estava definindo forças eletromotrizes e as correntes causadas por tais fluxos magnéticos variáveis [6].

O fluxo magnético pode ser definido como a quantidade de linhas de indução que atravessam uma determinada área A de uma espira imersa num campo magnético de indução B,

$$
\Phi=B \cdot A \cdot \cos \theta
$$

No SI, $\Phi$ é dado em weber $(\mathrm{Wb}), \mathrm{B}$ em tesla $(\mathrm{T})$ e $\mathrm{A}$ em $\mathrm{m}^{2} . \theta$ é o ângulo entre os vetores B e A.

A variação de fluxo magnético (eq. 1) em um dado circuito produz uma força eletromotriz induzida (fem), denotada por $(\varepsilon)$. A fem. numa espira é diretamente proporcional ao fluxo magnético $\Phi$ que a atravessa e é inversamente proporcional ao intervalo de tempo $\Delta t$ em que essa variação ocorre (Lei de Faraday),

$$
\varepsilon=-\frac{\Delta \phi}{\Delta t}
$$

onde $\varepsilon$ é dado em volts $(\mathrm{V})$, no SI. O sinal negativo relaciona-se com a Lei de Lenz, a qual estabelece que em uma corrente elétrica induzida em um dado circuito, gera um campo magnético que se opõe a variação do fluxo magnético que induziu a corrente.

\subsection{Energia e Potência}

A energia envolvida no processo do movimento cinético do vento que é a energia cinética de uma determinada massa de ar $m$ em movimento a uma velocidade $v$ e é dada por:

$$
E=-\frac{1}{2} m v^{2}
$$

A eq. (3) representa a energia cinética proveniente do movimento das massas ar envolvidas na produção de Energia Eólica. A unidade de E no SI é o joule (J).

Sendo a vazão dada por,

$$
Z_{V}=\frac{d V}{d t}=\frac{A v(d t)}{d t}=A v \Rightarrow Z=A v
$$

onde $\mathrm{Z}$ é dada $\mathrm{em} \mathrm{m}^{3} / \mathrm{s}(\mathrm{SI})$.

Considerado a massa específica $\rho$ do fluido uniforme, pode-se escrever para a vazão média,

$$
Z_{m}=\rho Z_{V}=\rho A v
$$

onde, $\rho$ é dado em $\mathrm{kg} / \mathrm{m}^{3}$, no SI.

Sabe-se que a massa específica $\rho$ é dada por,

$$
\rho=\frac{m}{V}
$$


Substituindo-se a expressão (6) em (3), obtém-se,

$$
E=\frac{1}{2} \rho V v^{2}
$$

No SI, E é dado em joule (J).

Sendo $x=v . t$ e $V=A . x$, substituindo em (7), tem-se,

$$
E=\frac{1}{2} \rho A v t v^{2}=\frac{1}{2} \rho A t v^{3}
$$

Sendo que a potência disponível que passa pela área $A$ é a derivada da energia com relação ao tempo,

$$
P_{D}=\frac{d E}{d t}
$$

com $\mathrm{P}_{\mathrm{D}}$ em watts $(\mathrm{W})$, no SI.

Substituindo-se (8) em (9), obtém-se:

$$
P_{D}=\frac{1}{2} \rho A v^{3}
$$

A expressão (10) representa a potência disponível no vento e é proporcional à massa específica, a área de secção transversal e ao cubo da velocidade.

Definindo-se uma constante $k$, tal que,

$$
k=\frac{1}{2} \rho A
$$

Então, reescreve-se a equação (10) em termos da constante $k$ da seguinte forma:

$$
P=k v^{3}
$$

A fundamentação teórica dos conceitos antes das atividades (experimentos reais e virtuais, e vídeo), é imprescindível para o êxito destas. O professor deve abordar de forma conjunta, ao trabalhar junto à turma, tanto o tópico sobre a energia eólica bem como os conceitos relacionados a esta. Durante a realização das atividades o professor deve se comportar como facilitador da aprendizagem, sugerindo as manipulações que os alunos devem fazer e questionando o que eles podem observar durante cada etapa, fazendo uma anotação detalhada das conclusões a que chegam, para depois compartilhar com toda a turma. Daí, deve novamente fazer questionamentos que melhorem os resultados e que induzam os alunos a chegarem as conclusões desejadas.

A seguir será feita uma breve abordagem das teorias de Piaget e Vygotsky, que embasam este trabalho.

\subsection{Piaget e Vygotsky}

Segundo PIAGET (1970) [7] o ser humano, desde a infância até a fase adulta, constrói seu próprio conhecimento (daí a origem do termo "construtivista") e o desenvolvimento cognitivo ou mental se dá pelos processos conceituais de assimilação, acomodação, esquemas e equilibração, esse último princípio fundamental de sua teoria, apesar de que para ele a aprendizagem ocorre quando há acomodação.

Por isso é importante confrontar o aluno com questões que sejam pertinentes e níveis de dificuldades. A Física tem várias dessas características desafiadoras, que leva o aprendiz a reestruturar seu conhecimento de uma forma mais organizada e construtiva MOREIRA (1999) [8].

De acordo com NEVES et al. (2006) [9], para Vygotsky o desenvolvimento humano é determinado pelo meio social através da tomada de conhecimento pela imitação ou mediação. Para VYGOTSKY (1991) [10], a cultura e a sociedade no qual o indivíduo está inserido são 
fatores determinantes ao seu aprendizado, ou seja, a teoria fundamenta-se no contexto sócio histórico do indivíduo e não apenas em seu desenvolvimento cognitivo.

Os pilares do pensamento vygostskyano estão fundamentados em três ideias centrais que são as funções psicológicas imprescindíveis ao aprendizado, o funcionamento delas, que tem como fundamentação as relações histórico-sociais e por fim, a relação entre o indivíduo e o mundo que é mediada por instrumentos e símbolos (signos). Nessa teoria os instrumentos fazem parte culturalmente das sociedades, e que vislumbram as inerentes características do aprendiz visto que os instrumentos são ferramentas utilizadas para execução de algo, enquanto os signos são significados de diversas coisas do dia a dia das pessoas. Assim a aprendizagem se mostra eficiente se for levada por esse lado, mostrando que é na socialização que os processos mentais são elencados segundo MOREIRA (1999) [8].

Além disso, as interações que favorecem o desenvolvimento incluem a ajuda ativa, a participação ou a construção de pontes de um adulto ou alguém com mais experiência nesse processo mediatório. No entanto, aquilo que a criança ainda não é capaz de realizar sozinha, pode-se auxiliá-la de muitas formas, desde que seja dentro da zona de desenvolvimento proximal (ZDP), zona imaginária que demonstra a diferença quando a criança precisa de ajuda ou não para executar certas atividades [11].

Ainda, segundo MOREIRA (1999) [8], Vygotsky define a ZDP como a distância entre o nível de desenvolvimento cognitivo real do indivíduo, tal como medido por sua capacidade de resolver problemas independentemente, e o seu nível de desenvolvimento potencial, tal como medido através da solução de problemas. Nesse processo de mediação o professor é responsável por averiguar se o significado que o aluno compreendeu é aceito, ou compartilhado socialmente.

Nessa perspectiva entende-se que o aprendizado ocorre de forma efetiva, quando há o compartilhamento de significados entre os sujeitos, no caso, professor e aluno, isto é, um compartilhamento transparente, bem definido, com o auxílio de instrumentos e signos capazes de implementar uma didática satisfatória mediada pela interação sociocultural dos atores envolvidos nesse processo da aprendizagem de fato significativa.

\section{MATERIAIS E MÉTODOS}

Esta pesquisa tem como público 17 turmas (407 alunos) da terceira série do Ensino Médio das escolas da rede pública de ensino da cidade de Marabá, Pará: Escola Estadual Dr. Gaspar Vianna e a Escola Estadual Plínio Pinheiro. As turmas de $3^{\mathrm{a}}$ séries do Ensino Médio das escolas foram divididas em dois grupos: o grupo A (13 turmas) e o grupo B (4 turmas), sendo que nas turmas do grupo A foram ministradas aulas sobre energia eólica e conceitos físicos correlatos e realizadas as simulações computacionais, a apresentação do vídeo e a realização da atividade experimental. Contudo, nas turmas do grupo B (turma piloto), foram ministradas apenas aulas dos conteúdos baseados no tema proposto e o referido tema.

Quanto as etapas de execução, o trabalho foi dividido em quatro momentos distintos: inicialmente, aplicou-se um questionário avaliativo (triagem) com o intuito de mensurar o nível de compreensão dos discentes a respeito do assunto. Num segundo momento foram ministradas aulas sobre o conteúdo de energias renováveis, especialmente, sobre a energia eólica em conjunto com os tópicos de Física relacionados à referida energia eólica. Posteriormente, foram feitas simulações sobre o tema, realização de experimento e apresentação do vídeo aula e, finalmente, aplicou-se uma atividade avaliativa para os dois grupos com intuito de verificar o nível de aprendizado em relação ao tema abordado. Também foi realizado um segundo questionário, apenas com o grupo A, para verificar o grau de aceitação da metodologia.

Em relação as simulações virtuais, utilizou-se o simular gratuito Physics Education Technology $\left(\right.$ PhET $\left.^{\circledR}\right)$ disponível em [1]. O PhET é um projeto da Universidade do Colorado, concebido para desenvolver simulações de alta qualidade, não apenas na área de Física como em outras áreas da ciência.

No experimento sobre a indução eletromagnética (Fig. 1), realizado no Phet, o aluno tem uma representação verossímil do fenômeno real. Como já foi destacado, é importante que o professor facilite o processo da aprendizagem sugerindo os botões e ações a serem realizadas, fazendo questionamentos sobre o que os alunos observam em cada etapa, para que possam chegar às conclusões esperadas. 
Usando a simulação é possível medir a variação do campo magnético, visualizar as linhas de campo magnético de um ímã, como se comporta uma bússola próxima aos polos de um ímã, e a variação do fluxo magnético que produz uma corrente induzida na bobina, ou seja, todos os conceitos fundamentais sobre a indução eletromagnética podem ser verificados. Segundo PRATA (2007) [12], num espaço educacional o conhecimento e a experiência precisam estar atrelados aos experimentos reais para que se possa obter uma aprendizagem satisfatória.

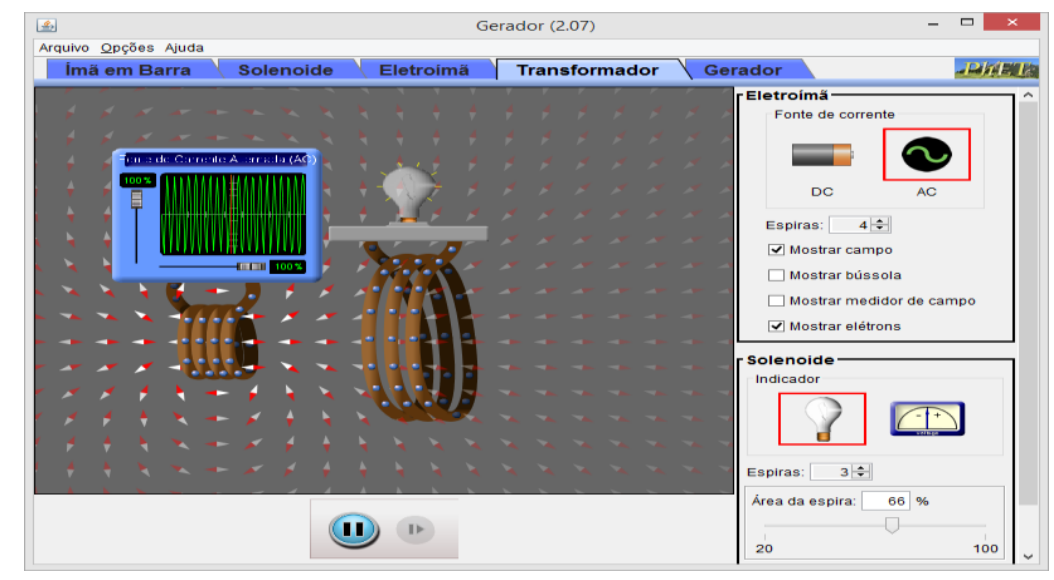

Figura 1: Experimento "virtual" no software Phet sobre indução eletromagnética [1].

Foi feita também uma atividade experimental que envolvia o conceito de indução eletromagnética onde foi possível demonstrar aos alunos a corrente induzida, quando se varia o fluxo magnético no interior de uma bobina. Nesse experimento (Fig. 2), foram utilizados eletroimãs montados num pedaço de cano de $\mathrm{PVC}$, e sobre um outro pedaço de cano de maior diâmetro foi fixada uma bobina (com 400 espiras) e um led como indicador óptico para informar visualmente o surgimento da corrente induzida.

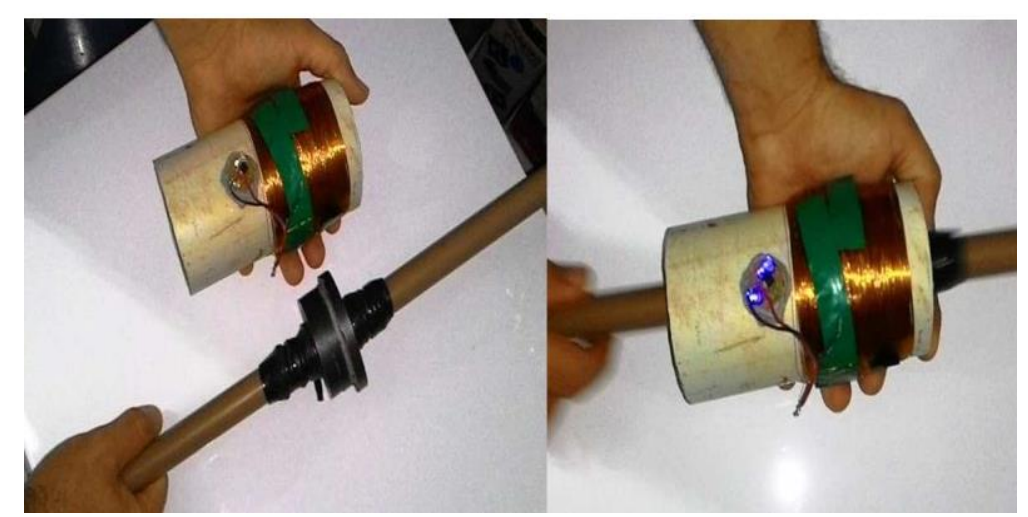

Figura 2: Experimento de indução eletromagnética.

Também foi apresentado um vídeo sobre a formação dos ventos. Após a apresentação deste, foram feitos questionamentos sobre o processo de formação dos ventos com intuito de se verificar a compreensão a respeito do assunto abordado.

Posteriormente à ministração das aulas, as turmas foram submetidas a uma atividade avaliativa com 7 questões de múltipla escolha, com o objetivo de avaliar o nível de compreensão dos estudantes sobre conceitos abordados. A atividade consistia em questões de múltipla escolha subsidiadas pelo tema.

Finalmente, foi novamente realizado um questionário, com o intuito de inferir o grau de satisfação dos alunos, quanto ao uso da metodologia adotada.

\section{RESULTADOS E DISCUSSÃO}

Neste tópico serão apresentados os resultados obtidos e as discussões sobre eles. 


\subsection{Questionário Inicial (triagem)}

A maior faixa etária dos entrevistados está entre 15 a 24 anos (97,05\%). Quando perguntados, "Você sabe o que são energias renováveis? ", 43,23\% não souberam responder.

A Figura 3, mostra a resposta para a questão "Marque com um x as fontes que não são energias renováveis". Do total de alunos, 79,90\% erraram a questão, $19,90 \%$ não souberam responder, e apenas $0,25 \%$ acertaram.

Quando perguntados sobre "Qual a sua opinião com relação à utilização de energias renováveis? ", a maioria respondeu que não sabe o que são energias renováveis, demonstrando mais uma vez pouquíssimo conhecimento do assunto. 29,24\% afirmaram que é rentável o uso das renováveis, e $20,15 \%$ dizem serem nocivas, o que demostra total falta de conhecimento sobre as energias renováveis.

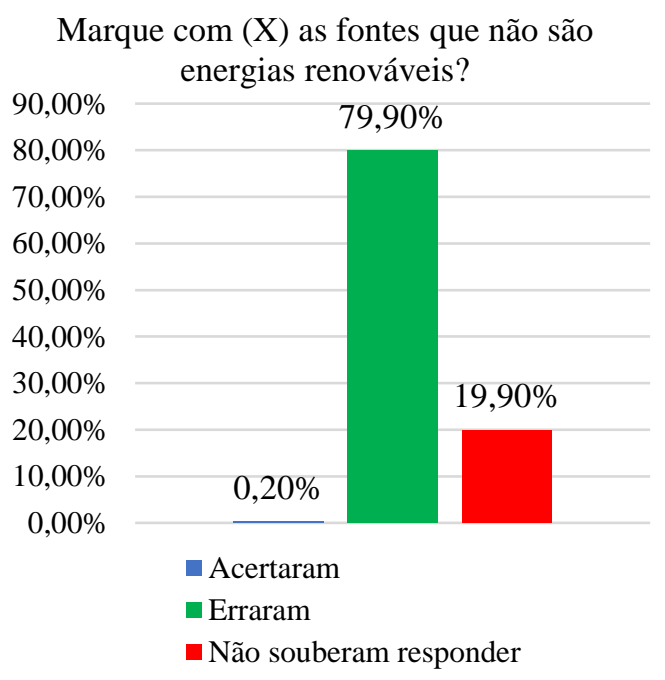

Figura 3: Questão sobre fontes de energia renovável.

\section{Considera que o investimento pessoal em energias renováveis seja um bom investimento para o futuro?}

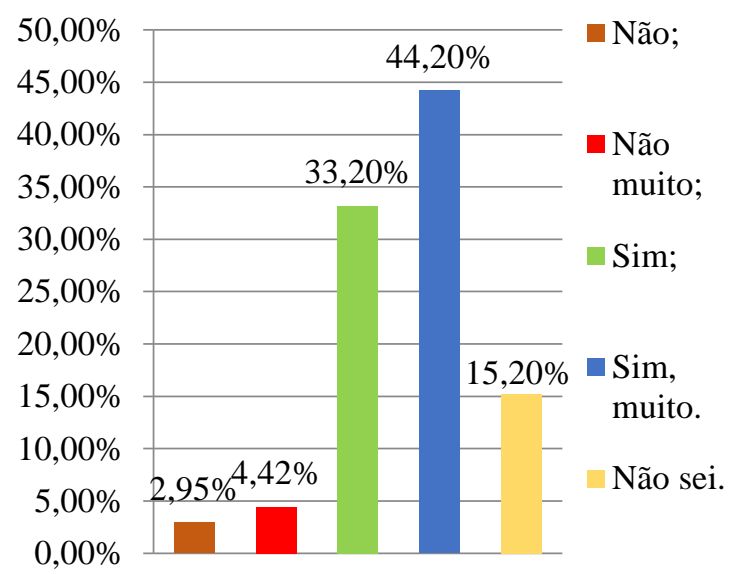

Em resposta à pergunta "Considera que o investimento pessoal em energias renováveis seja um bom investimento para o futuro?" (Fig. 4), a maioria concordou com um bom investimento, sendo que $33,20 \%$ responderam sim e 44,20\% sim muito. Os demais responderam de forma equivocada.

A partir dos resultados observados fica claro a falta de conhecimento dos alunos a respeito do tema das energias renováveis. Esses resultados só evidenciam que a escola não está desempenhando o seu papel quanto a formação de cidadãos conscientes sobre a realidade da mudança climática em nosso planeta.

A seguir serão apresentados e comentados os resultados da avaliação.

\subsection{Avaliação}

A Figura 5 apresenta o resultado da avaliação aplicada aos grupos A e B. Verifica-se que o grupo A teve um desempenho significativamente melhor que o grupo B. Isto demonstra a efetividade da metodologia adotada. A seguir será feito um breve comentário sobre as questões e os respectivos índices de acertos dos referidos grupos. 


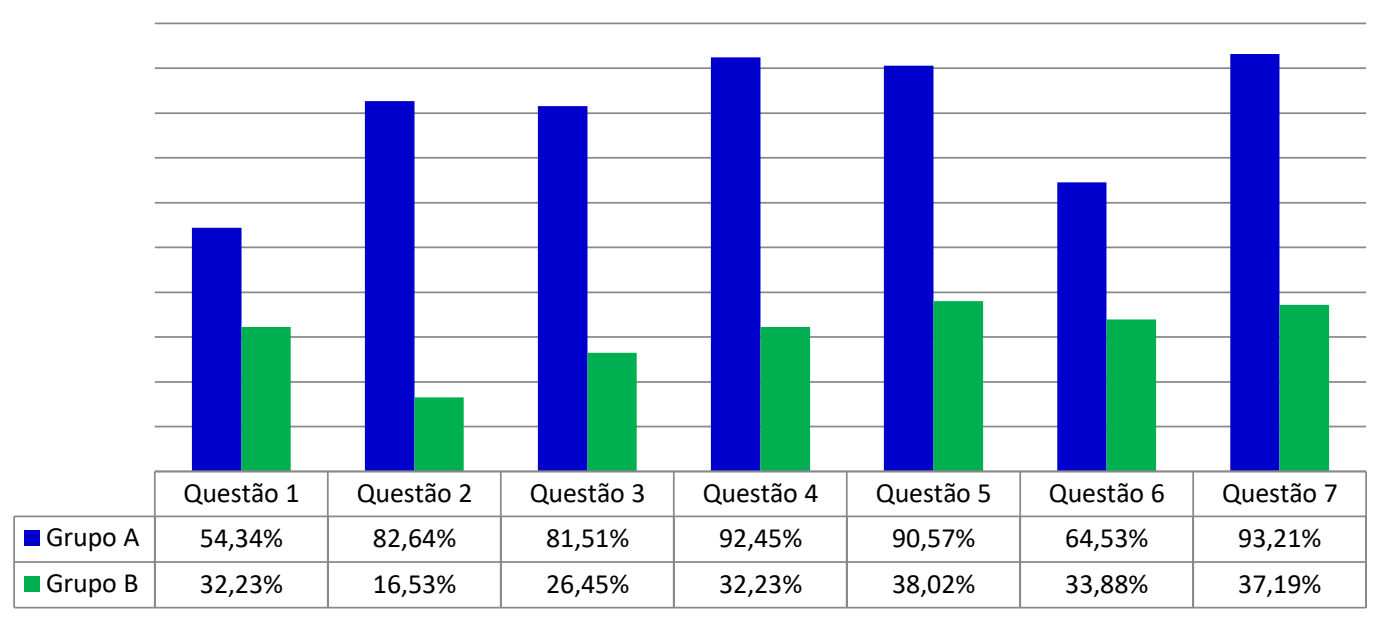

Figura 5: \% de acertos dos Grupos A e B.

A questão 1 trata do cálculo da potência de um aerogerador. Os alunos, de um modo geral, obtiveram baixos percentuais de acertos. Ainda assim, o grupo A obteve um melhor desempenho. Essa questão exigiu habilidade em conhecer as grandezas Físicas, as unidades fundamentais de medidas e ainda conversão entre elas. A questão 2, teórica, não exigia cálculos como na questão 1 , porém, inqueriu um conhecimento prévio sobre as matrizes energéticas e as condições adequadas para sua utilização, visto que considera as características de um lugar plano com ventos constantes. O grupo A obteve o percentual de 82,64\%, enquanto que o grupo B obteve apenas $16,53 \%$ de acertos. A questão 3, também teórica, exigiu que o aluno fosse capaz de distinguir as fontes de energias renováveis das não renováveis, o grupo A obteve 81,51\% contra $26,45 \%$ do grupo $\mathrm{B}$.

A questão 4, inqueria aos alunos, que citassem em que regiões ou lugares do Brasil estão os maiores potenciais de energia eólica. Os resultados de acertos entre os dois grupos foram divergentes com diferenças de percentuais enormes. Na questão 5, arguiu-se o aluno sobre uma fonte alternativa de menor impacto ambiental. Novamente, o grupo A destacou-se com relação ao grupo B. Analisando-se a questão 6 observa-se uma queda do número de acertos em ambos grupos. Esse fato justifica-se devido a questão tratar de um caráter técnico e complexo que é o processo de conversão da energia cinética da massa de ar em energia elétrica. Ainda assim, o grupo A apresentou maior percentual de acertos com relação ao grupo B, cujo percentual foi de apenas $33,88 \%$ dos acertos.

$\mathrm{Na}$ última questão, indagou-se sobre qual região do Brasil fica o maior potencial de energia eólica? Apesar da simplicidade da questão o grupo B obteve apenas 37,19\% de acertos. Por outro lado, o grupo A obteve quase $100 \%$ de acertos.

Percebe-se claramente que o desempenho do grupo A em relação ao do grupo B foi muito melhor. Apesar de ambos os grupos haverem tido a mesma carga horária nas aulas, é claro que o fato do grupo A haver tido uma metodologia de ensino focada em experimentos, tanto virtuais como reais, além do vídeo apresentado, possibilitou que estes tivessem um aprendizado mais lúdico, mais participativo, mais significativo. Isto evidentemente, contrastou com as aulas apenas teóricas do grupo B. O resultado não poderia ser diferente.

\subsection{Questionário Final}

Visando verificar as concepções dos alunos com relação ao uso das energias renováveis, foi feito este questionário final. Cabe destacar que houve uma mudança significativa e muito positiva na opinião dos discentes com relação ao tema em questão.

A Figura 6 apresenta as respostas dos alunos, quando inquiridos se concordavam com a contribuição do ensino sobre as energias renováveis, como auxiliar do processo de ensinoaprendizagem de Física. Verifica-se que a maioria absoluta $(98,11 \%)$ concorda. Fica assim evidente que ferramentas utilizadas foram satisfatórias ao aprendizado dos alunos. 
Você acha que o ensino de energias renováveis contribuiu para o ensino - aprendizagem de física?

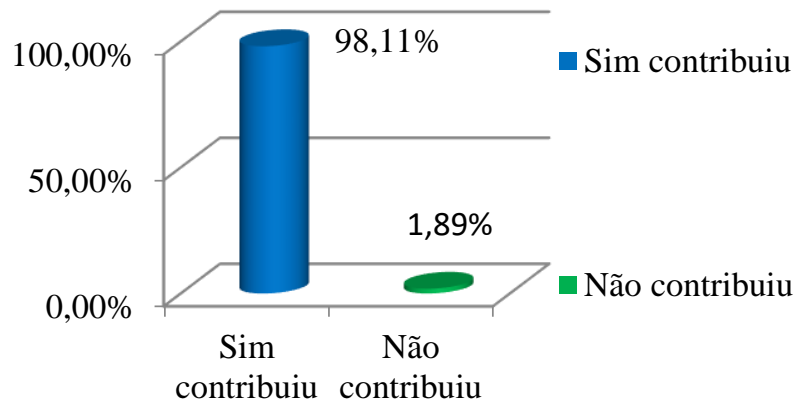

Figura 6: Contribuição das energias renováveis com o ensino-aprendizagem de Física.

Quando questionados sobre o uso dos experimentos (reais e virtuais) como auxiliares no aprendizado sobre as energias renováveis, $78,87 \%$ responderam que acharam ótimo, 20,38\% declararam bom e apenas $0,76 \%$ acharam regular.
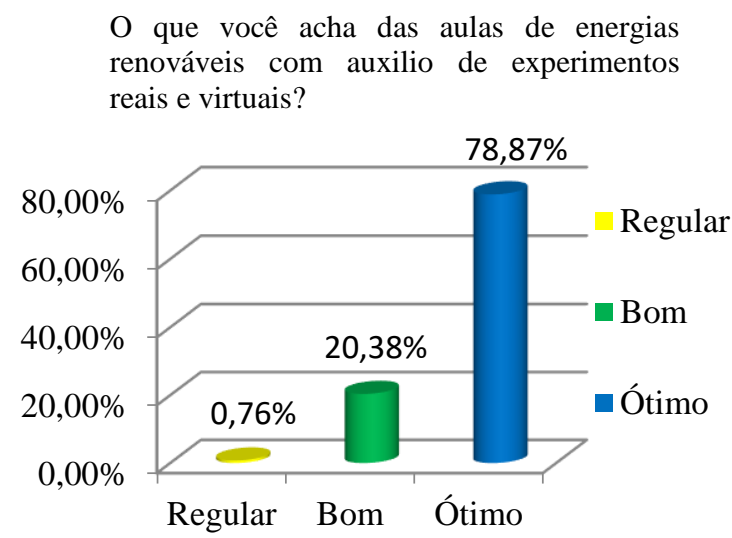

Figura 7: Contribuição nas aulas sobre energias com o auxílio de experimentos reais e virtuais.

Sobre a importância do uso do simulador em sala de aula, para facilitar o aprendizado do funcionamento das usinas eólicas (Fig. 8), cerca de 83,02\% afirmaram que o uso de simular é ótimo, $15,85 \%$ dos alunos, classificou a utilização do simular como bom, e somente, $1,13 \%$ classificaram como regular.

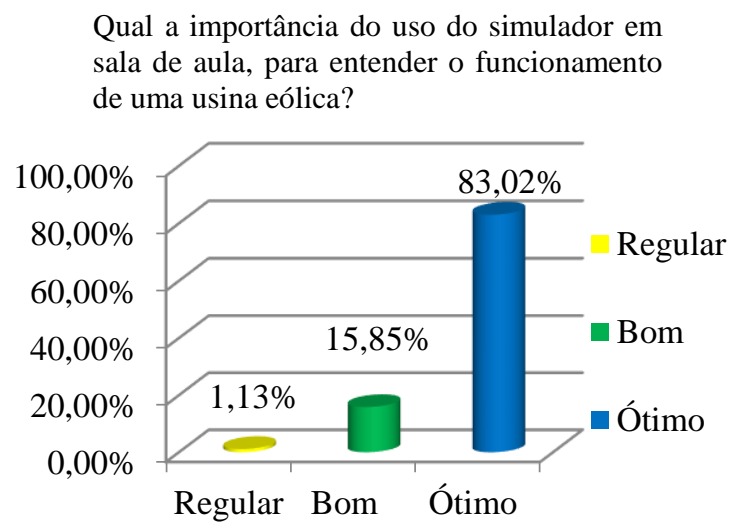

Figura 8: Respostas dos alunos sobre o uso do simulador para a compreensão do tema da energia eólica. 
A partir do resultado obtido neste questionário, fica mais evidente ainda que o uso dos simuladores, a apresentação do vídeo e a realização do experimento real, facilitam a compreensão sobre o tema em questão. Ressalta-se, porém, que tais recursos, não são uma panaceia que resolvem todos os problemas do ensino. São apenas instrumentos, dentre tantos outros, que estão disponíveis ao professor para uma prática didático-pedagógica que, se trabalhada de forma adequada, mostrar-se-á satisfatória. Convém destacar também que essas práticas não substituem a aulas teóricas, mas sim, são um complemento a elas.

A transposição didática do abstracionismo de um conceito para a vinculação concreta de um fenômeno dado foi observada em todas as fases desse trabalho. Nesse sentido, os PCN (2002) [13] afirmam que a metodologia utilizada pode ir tanto do vivencial para o abstrato, quanto deste para a situação de aprendizagem.

\section{CONCLUSÃO}

Desafiador tanto para alunos, quanto para professores, o tema sobre as energias renováveis, trouxe para a reflexão a possibilidade do uso de recursos didáticos metodológicos eficazes para a melhoria do ensino de Física. Apesar da grande divulgação em massa, esse assunto nem sempre é temática abordada pelos professores das escolas públicas do país.

Constatou-se ainda, que os alunos apresentaram muitas dificuldades com relação aos cálculos algébricos, uma vez que, neste caso, seria necessária uma abordagem que focasse mais na revisão dos conceitos matemáticos, o que, evidentemente, não foi o foco neste trabalho.

Os resultados deste trabalho destacam a importância deste tema, aliado a utilização de simuladores interativos, vídeos e experimentos reais, que se tornam facilitadores ao aprendizado pelos alunos dos conceitos que até então eram tidos como complexos. No contexto deste trabalho, ficou evidente o desdobramento proximal entre alunos e os conceitos. Isto foi perceptível em todas as fases.

Assim, os resultados foram satisfatórios, mostrando que este tipo de metodologia é eficiente, se devidamente aplicada e, o tema gerador, se torna fundamental a ser usado como subsunçor AUSUBEL (2003) [14] para o aprendizado dos conceitos físicos, sem mencionar a atualidade do tema no contexto mundial. Desse modo, os autores deste trabalho recomendam fortemente o uso desse tipo de estratégia no ambiente de sala de aula, para melhorar o aprendizado dos conceitos de Física pelos alunos e, evidentemente, inseri-los em uma sociedade mais comprometida com os problemas ambientais e sociais, de modo que venham a fazer parte da solução deste grande impasse que nossa sociedade moderna vive.

\section{REFERÊNCIAS BIBLIOGRÁFICAS}

1. Phet. Interactive Simulations [internet]. Colorado, 2016 Disponível em: < https://phet.colorado.edu/pt_BR/> Acesso em: 18 de nov. 2016.

2. Fukugita M, Peebles PJE. The Cosmic Energy Inventory. The Astrophysical Journal 2004, jun;616:643-668, doi: 10.1086/425155

3. Dutra R. Energia Eólica. Princípio e Tecnologias. Centro de Referência para Energia Solar e Eólica Sérgio de Salvo Brito. São Paulo: CRESESB/CEPEL, 2008. Disponível em: < http://www.portalenergia.com/downloads/energia-eolica-principios-tecnologias.pdf> Acesso em: 18 de nov. 2016.

4. Yamamoto S, Fonseca E, Pisni F. Abeeólica. Boletim anual de geração eólica, 2015. Boletim de dados julho de 2015. Disponível em: <http://www.abeeolica.org.br/wpcontent/uploads/2016/08/Abeeolica_BOLETIM-2015_low.pdf> Acesso em: 18 de nov. 2016.

5. Ministério das Minas e Energia. Boletim Mensal de Monitoramento do Sistema Elétrico Brasileiro.[internet] Disponivel em: http://www.mme.gov.br/documents/10584/3308684/Boletim+de+Monitoramento+do+Sistema+El\%C3 \%A9trico+-+Novembro-2016.pdf/75f37a50-43f4-4c60-8043-7cfc7fb4c54f. Acesso em: 20 novembro 2016.

6. Tipler PA, Mosca G. Física: Eletricidade e magnetismo, Ótica. 5. ed. Rio de Janeiro: LTC; 2006 p436.

7. Piaget J. Genetic Epistemology. London: Columbia University Press; 1970.

8. Moreira MA. Teorias de Aprendizagem. São Paulo: EPU; 1999. 195 p. 
9. Neves RDA, Damiani MF. Vygotsky e as teorias da aprendizagem. UNIrevista; 2006.

10. Vygotsky LSA. FORMAÇÃO SOCIAL DA MENTE. 4. ed. São Paulo: Martins Fontes; 1991. 90 p.

11. Präss, AR (s.d.). Teorias de aprendizagem. Universidade Federal do Rio Grande do Sul. Instituto De Física. Disponivel em:Url: http://www.fisica.net/monografias/Teorias_de_Aprendizagem.pdf. Acesso em: 20 março 2016.

12. Prata CL, Nascimento, ACA Objetos de Aprendizagem: uma proposta de recurso pedagógico. Brasília: MEC, SEED; 2007. 154 p. ISBN: 978-85-296-0093-2. Disponivel em: http://www.oei.es/tic/livro.pdf. Acesso em: 20 março 2016.

13. BRASIL. PCN. Orientações Educacionais Complementares aos Parâmetros Curriculares Nacionais. Brasília: MEC; 2002.

14. Ausubel DP. Aquisição e Retenção de Conhecimentos: Uma Perspectiva Cognitiva. Lisboa: Paralelo; 2003. 